\title{
Tip60 Suppresses Cholangiocarcinoma Proliferation and Metastasis via PI3k-AKT
}

\author{
Yaodong Zhang Guwei Ji Sheng Han Zicheng Shao Zefa Lu \\ Liqun Huo Jiawei Zhang Renjie Yang Qinchao Feng Hao Shen \\ Hongwei Wang Xiangcheng Li
}

Key Laboratory on Living Donor Liver Transplantation, Ministry of Health, Department of Liver Surgery, First Affiliated Hospital of Nanjing Medical University, Nanjing, China

\author{
Key Words \\ Tip60 • Cholangiocarcinoma • Proliferation • Metastasis
}

\begin{abstract}
:
Background/Aims: Aberrant expression of Tip60 is associated with progression in many cancers. However, the role of Tip60 in cancer progression remains contradictory. The aim of this study was to investigate the clinical significance, biological functions and underlying mechanisms of Tip60 deregulation in cholangiocarcinoma (CCA) for the first time. Methods: Quantitative real-time PCR (QRT-PCR), western blotting and immunohistochemistry staining (IHC) were carried out to measure Tip60 expression in CCA tissues and cell lines. KaplanMeier analysis and the log-rank test were used for survival analysis. In vitro, cell proliferation was evaluated by flow cytometry and CCK-8, colony formation, and EDU assays. Migration/ invasion was evaluated by trans-well assays. Phosphokinase array was used to confirm the dominant signal regulated by Tip60. Tumor growth and metastasis were demonstrated in vivo using a mouse model. Results: Tip60 was notably downregulated in CCA tissues, which was associated with greater tumor size, venous invasion, and TNM stage. Down-regulation of Tip60 was associated with tumor progression and poorer survival in CCA patients. In vitro and in vivo studies demonstrated that Tip60 suppressed growth and metastasis throughout the progression of CCA. We further identified the PI3K/AKT pathway as a dominant signal of Tip60 and suggested that Tip60 regulated CCA cell proliferation and metastasis via PT3K-AKT pathway. Pearson analysis revealed that PTEN was positively correlated with the Tip60 level in CCA tissues. Conclusion: Tip60, as a tumor suppressor in CCA via the PI3K/AKT pathway, might be a promising therapeutic target or prognostic marker for CCA.
\end{abstract}

(C) 2018 The Author(s)

Published by S. Karger AG, Basel

Y. Zhang, G. Ji and S. Han contributed equally to this work.

\begin{tabular}{ll}
\hline Xiangcheng Li & Department of liver surgery, First Affiliated Hospital of Nanjing Medical University \\
& 300\# Guangzhou Road, Jiangsu Province, 210029 (China) \\
Tel. +8618951999088, E-Mail drxcli@njmu.edu.cn
\end{tabular}




\section{Cellular Physiology Cell Physiol Biochem 2018;50:611-628 \begin{tabular}{ll|l} 
DOI: 10.1159/000494183 & $\begin{array}{l}\text { O } 2018 \text { The Author(s). Published by S. Karger AG, Basel } \\
\text { www.karger.com/cpb }\end{array}$ \\
\hline and Biochemistry
\end{tabular}

\section{Introduction}

Cholangiocarcinoma (CCA), which includes intrahepatic cholangiocarcinoma (ICC) and extrahepatic cholangiocarcinoma (ECC), is an epithelial cell tumor arising from all levels of the bile ducts, and the incidence and prevalence of CCA has been notably increasing in the last decades [1, 2]. Anatomical classifications distinguish intra- (ICC) or extra-hepatic CCA (ECC), and ECC is further divided into hilar CCA located at the liver hilum, or distal CCA located near the pancreas [3,4]. The outcome of treatment at the advanced stage of CCA is still unsatisfactory, with a median survival of 6-12 months. It is particularly notable that ICC has a poorer prognosis than ECC, because the biological characteristics of ICC and ECC are different [5] .

Nucleosome acetyltransferase of histone $\mathrm{H} 4$ (NuA4) complex is the fusion of two yeast histone acetyl transferase (HAT) complexes, NuA4 and SWR1 [6-8]. Previous studies have proved that this complex is involved in transcriptional regulation, DNA repair, chromatin structure alteration, cell migration and invasion, mitosis, and genomic instability $[9,10]$. Tip60, a member of the MYST family, is expressed ubiquitously and is the acetyltransferase catalytic subunit of the human NuA4 complex. Tip60 has proved to be an essential protein and its function cannot be compensated by other members of the MYST family. Recently, many previous studies have shown the involvement of Tip60 in oncogenesis, and in resistance to cancer or potential anti-oncogenic activities $[11,12]$. Tip60 can play a part in oncogenesis though several connections with other subunits of the NuA4 complex, such as p400 and BRD8 $[13,14]$. Other studies have linked Tip60 to oncogenesis via interactions between Tip60 and other proteins such as RelA/p65 and C-Myc $[15,16]$. However, other studies have demonstrated that Tip60 may stimulate different tumor suppressor pathways, especially p53, the ING family, and retinoblastoma [17-20].

However, the relationship between CCA and Tip60 is still unknown. In the present study, we first detected that Tip60 was a tumor suppressor in both ICC and ECC tissues and vitro, and confirmed the correlation between Tip60 and CCA clinical parameters and prognosis. By investigating the role of Tip60 in CCA, the results suggested that Tip60 negatively regulated proliferation and metastasis though the PI3K-AKT pathway. Furthermore, we also confirmed the suppressive function of Tip60 in vitro and found a positive correlation between PTEN and Tip60 levels. Based on the data presented here, we aimed to investigate the contribution of Tip60 to CCA.

\section{Materials and Methods}

\section{Tissue Samples}

A total of 59 tumor specimens and matched para-tumor tissues were obtained from 30 ICC patients and 29 ECC patients without preoperative systemic chemotherapy, who underwent therapeutic resection of cholangiocarcinoma at The First Affiliate Hospital of Nanjing Medical University during 2010 - 2016. All CCA tissues were collected using protocols approved by the Ethics Committee of The First Affiliate Hospital of Nanjing Medical University, and written informed consent was obtained from every patient. All patients were diagnosed as cholangiocarcinoma based on postoperative pathological evidence.

\section{Cell Culture and Transfection}

All cell lines (RBE, QBC939, HCCC9810, HUCCT1, and HiBEC) were obtained from the Cell Bank of the Chinese Academy of Science (Shanghai, China). And RBE, QBC939, HCCC9810, HUCCT1 cell lines were derived from CCA cells, and HiBEC was the normal bile duct epithelial cells. Cells were maintained in DMEM medium (Gibco, USA) with $10 \%$ fetal bovine serum (Biological Industries, Israel), penicillin/ streptomycin 100 units $/ \mathrm{mL}$ at $37^{\circ} \mathrm{C}$ in a humidified incubator containing $5 \% \mathrm{CO}_{2}$. The control and Tip60 siRNA were obtained from Gene pharma pharmaceutical technology Co. Ltd. The Tip60-overexpressing plasmid was designed by Obio Technology. The siRNA targeting sequences were as follows: Tip60 (5'-3'):1'forward (CCACAGGAACUCACCACAUTT), reverse (AUGUGGUGAGUUCCUGUGGTT), 2'forward 


\section{Cellular Physiology Cell Physiol Biochem 2018;50:611-628 and Biochemistry Published online: 12 October 2018 \begin{tabular}{l|l} 
D 2018 The Author(s). Published by S. Karger AG, Basel \\
www.karger.com/cpb
\end{tabular}}

Zhang et al.: Tip60 Suppresses Cholangiocarcinoma via Pt3K/Akt

(GCAAUGAGAUUUACCGCAATT), reverse (UUGCGGUAAAUCUCAUUGCTT). The control target sequences were: forward (UUCUCCGAACGUGUCACGUTT), reverse (ACGUGACACGUUCGGAGAATT). The siRNA transfection assays were performed with Lipofectamine 2000 transfection reagent (Invitrogen, CA) in accordance with manufacturer's protocol.

\section{RNA Preparation and qRT-PCR}

Total RNA was extracted from tumor and para-tumor tissues or cultured cells using TRIzol solution (Invitrogen, China) following the manufacturer's protocol. The A260/A280 ratio was used to evaluate RNA purity. Quantitative real-time PCR was performed using the Thermal Cycler Dice Detection System with the SYBR Premix ExTaqTM (Takara Inc. Japan) (Table 1). GAPDH RNA was used as the endogenous control to which the data were normalized.

\section{Immunoblotting}

Cells and tissue samples were lysed using the RIPA protein extraction reagent kit (Beyotime, China) with $0.2 \%$ Phenylmethanesulfonyl fluoride (PMSF). Protein concentration was determined using the BCA assay (Pierce Thermo Scientific, Rockford, IL, USA). Cell lysates were separated by electrophoresis on SDSpoly-acrylamide gels and transferred onto nitrocellulose membranes. Membranes were reacted with the indicated antibodies. The proteins were labeled with specific antibodies against Tip60(1:500, Proteintech Group, Inc, USA); E-cadherin, N-cadherin, Vimentin(1:1000, Proteintech Group, Inc, USA); And GAPDH, Cyclin-D1, PI3K, p-PI3K, AKT, P-AKT(Ser473), PTEN(1:1000, Cell Signaling Technology, Danvers, MA, USA) The signal was monitored and protein expression was quantified using the NIH Image J software (National Institutes of Health, Bethesda, MD).

\section{Immunohistochemical Staining}

After 4\% paraformaldehyde fixation, the sections were deparaffinized. Antigens from the slides were retrieved by heating for $30 \mathrm{~min}$ in citrate buffer, $\mathrm{pH}$ 6.0. The slides were labeled with primary antibody in a blocking solution at $4^{\circ} \mathrm{C}$ overnight, followed by counterstaining with hematoxylin. Light microscopy (Nikon, Tokyo, Japan) was used to acquire the images, and NIS-Elements v4.0 software was used to quantify the staining (Nikon, Tokyo, Japan).

\section{Evaluation of Immunostaining}

Hematoxylin and eosin (H\&E) staining was performed via standard procedures. Tissue microarray 1(TMA1) and TMA2 containing 114 cases of ICC, and TMA4 and TMA5 containing 99 ECC specimens and corresponding non-cancerous tissues were obtained from The First Affiliate Hospital of Nanjing Medical University. Scoring was conducted based on the percentage of positively-stained cells $(0-5 \%$ scored 0 , 6-35\% scored 1, 36-70\% scored 2, and more than 70\% scored 3) and staining intensity (no staining scored 0 , weakly staining scored 1 , moderately staining scored 2 and strongly staining scored 3 ). The final score was calculated using the percentage score $\times$ staining intensity score as follows: "-" for a score of 0-1, "+" for a score of 2-3, "++" for a score of 4-6 and "+++" for a score of $>6$. Low expression was defined as a total score $<4$ and high expression as a total score $\geq 4$. These scores were determined independently by two senior pathologists in a blinded manner, and positive staining in the hepatic tissue was excluded from scoring.

\section{Invasion Assays}

Cell migration was assayed using modified Boyden chambers consisting of trans-well membrane filters (Corning Costar, Cambridge, MA, USA). Membranes were coated with $1 \mathrm{mg} / \mathrm{ml}$ of Matrigel (BD Biosciences) for cell invasion assays. CCA cells $(2 \times 105$ cells $)$ were suspended in serum-free media and added to the upper chamber. Serumpositive media were used as chemoattractant in the lower chamber. After 36 $\mathrm{h}$ (HUCCT1 and QBC939

Table 1. Primers used in the study

\begin{tabular}{lcc}
\hline Gene Name & Forward & Reverse \\
\hline Tip60 & GGGGAGATAATCGAGGGCTG & TCCAGACGTTTGTTGAAGTCAAT \\
E-cadherin & CGAGAGCTACACGTTCACGG & GGGTGTCGAGGGAAAAATAGG \\
N-cadherin & TCAGGCGTCTGTAGAGGCTT & ATGCACATCCTTCGATAAGACTG \\
Vimentin & GACGCCATCAACACCGAGTT & CTTTGTCGTTGGTTAGCTGGT \\
PTEN & TGGATTCGACTTAGACTTGACCT & GGTGGGTTATGGTCTTCAAAAGG \\
Cyclin D1 & GCTGCGAAGTGGAAACCATC & CCTCCTTCTGCACACATTTGAA \\
GAPDH & GGAGCGAGATCCCTCCAAAAT & GGCTGTTGTCATACTTCTCATGG \\
\hline
\end{tabular}




\section{Cellular Physiology Cell Physiol Biochem 2018;50:611-628 and Biochemistry \begin{tabular}{l|l} 
DOI: 10.1159/000494183 & O 2018 The Author(s). Published by S. Karger AG, Basel \\
wwww.karger.com/cpb
\end{tabular}

cells), and $48 \mathrm{~h}$ (RBE and HCCC9810 cells), the number of crystal violet-stained cells on the lower surface was counted as described previously [21].

\section{MTT Cell Proliferation Assay}

A total of 2, 000 cells were plated onto flat-bottomed 96-well plates and maintained overnight. Cells were incubated with $20 \mathrm{ml}$ of MTT (3-(4,5-dimethylthiazol-2-yl)-2, 5-diphenyltetrazolium bromide) for $2 \mathrm{~h}$. A volume of $200 \mathrm{ml}$ of DMSO was added and the absorbance measured at $492 \mathrm{~nm}$.

\section{EdU Pulse Chase Incorporation}

Cell proliferation was detected by EdU (5-ethynyl-2 0 -deoxy uridine) assay using the Cell-Light EdU DNA Cell Proliferation Kit (RiboBio, Shanghai, China). Cells were seeded in each well of 6-well plates for transfection with siRNA, lentivirus, or negative control (NC). Nucleic acids in all cells were stained with DAPI Dye. The Edu pulse chase incorporation and cell proliferation rate were applied according to the manufacturer's instructions. Images were taken using a fluorescence microscope (Olympus FSX100).

\section{Flow Cytometric Analysis of Cell Cycle Progression}

Cells were cultured for $24 \mathrm{~h}$ in 24 well plates prior to cell cycle analysis. The cells were then fixed with $70 \%$ cold ethanol overnight, washed once with phosphate-buffered saline (PBS), and resuspended in $500 \mu \mathrm{L}$ of PBS containing $100 \mu \mathrm{g} / \mathrm{mL}$ RNase for $30 \mathrm{~min}$ at $37^{\circ} \mathrm{C}$, and incubated (for $15 \mathrm{~min}$ ) with the nuclear stain PI (MultiSciences Biotech Co., Ltd.) at a final concentration of $40 \mu \mathrm{g} / \mathrm{ml}$. We analyzed $1 \times 10^{4}$ cells/ sample using a BD AccuriC6 flow cytometer (BD Biosciences, USA).

\section{Colony Forming Assay}

Forty-eight hours after siRNA and lentiviral vector transfections, cells were re-plated. Subsequently, cells were incubated for an additional 14 days at $37^{\circ} \mathrm{C}$ to allow for colony formation. Colony immobilization was maintained with $-20^{\circ} \mathrm{C}$ methyl alcohol for 30 minutes, cells were then stained with $0.5 \%$ crystal violet and counted. Results were quantified using Image J software.

\section{In vivo Tumorigenicity and Metastasis Assays}

Animal experiments were performed with the approval of the Animal Center of Nanjing Medical University use committees. BALB/C athymic nude mice were housed under specific pathogen-free conditions. CCA cells $\left(2 \times 10^{6}\right)$ transfected with lentivirus were injected into the hind limbs of mice to generate xenograft tumors. Tumor size was measured, and tumor volume was determined using the formula: $0.5 \times$ length $\times$ width $^{2}$. For metastasis assays, cells were resuspended in PBS at a concentration of $2 \times 10^{7}$ cells $/ \mathrm{ml}$. A volume of $0.1 \mathrm{~mL}$ of suspended QBC939, Tip60 inhibited, or Tip60 overexpressed QBC939 cells were injected into the tail veins. All mice were sacrificed 6 weeks after inoculation, and the metastatic nodes in the lungs were counted and examined by necropsy. Metastasis was monitored using the IVIS@ Lumina II system every 5 days.

\section{Phosphokinase Array}

The human phosphokinase array kit (ARY003B, R\&D system, Minneapolis, MN) containing 43 phosphokinases printed in duplicate was used to screen the signaling pathways. Briefly, the $80 \%$ confluent cells were lysed with lysis buffer containing phosphatase- and protease-cocktail inhibitors (Roche, Mannheim, Germany) and incubated at $4{ }^{\circ} \mathrm{C}$ for $15 \mathrm{~min}$. Cell lysate was obtained after centrifugation at 12 , $000 \mathrm{~g}, 4^{\circ} \mathrm{C}$, for $15 \mathrm{~min}$ and the total protein was quantified using the Bio-Rad Protein Assay Dye Reagent Concentrate (Bio-Rad, Hercules, CA) according to the instructions of the manufacturer. Total protein lysate $(600 \mu \mathrm{g})$ was incubated with an antibody-array membrane at $4^{\circ} \mathrm{C}$ overnight. The membrane was then incubated with cocktail-detection antibody and streptavidin horseradish peroxidase. The signals were detected using the Chemireagent provided in the same kit and quantified using an Image Quant ${ }^{\mathrm{TM}}$ Imager (GE Healthcare Bioscience AB, Uppsala, Sweden).

\section{Statistics}

Results were expressed as mean \pm standard deviation (SD) of three independent experiments unless otherwise specified. Data were analyzed by two-tailed, unpaired Student's $t$ test between any two groups 
and by One-Way ANOVA followed by Bonferroni test for multiple comparisons. These analyses were performed using GraphPad Prism Software Version 5.0 (GraphPad Software Inc., La Jolla, CA). P-value of $<0.05$ was considered statistically significant.

\section{Results}

Tip60 was downregulated in CCA and served as a prognostic factor

While investigating the role of Tip60 in CCA progression, we observed a decreasing trend in Tip60 mRNA levels from para-tumor tissues to ICC and ECC (Fig. 1A), which implies decreasing Tip60 expression during malignant $\mathrm{tr}$ a n s for m a t i o n . Additionally, we found that Tip60 was further down-regulated in ICC and ECC compared with the para-tumor tissues at the protein level (Fig. 1B). Next, by large scale immunohistochemical analysis in a tissue microarray containing 114 cases of ICC and 99 ECC specimens and pathologist-certified and clinically annotated CCA specimens, we found that Tip60 was down-regulation in CCA tissues (Fig. 1C) and was negatively correlated with worse overall survival (OS) (Fig. 1D). Together, these results revealed that Tip60 expression was significantly decreased in CCA, and decreased Tip60 was associated with poor prognosis in both ICC and ECC.

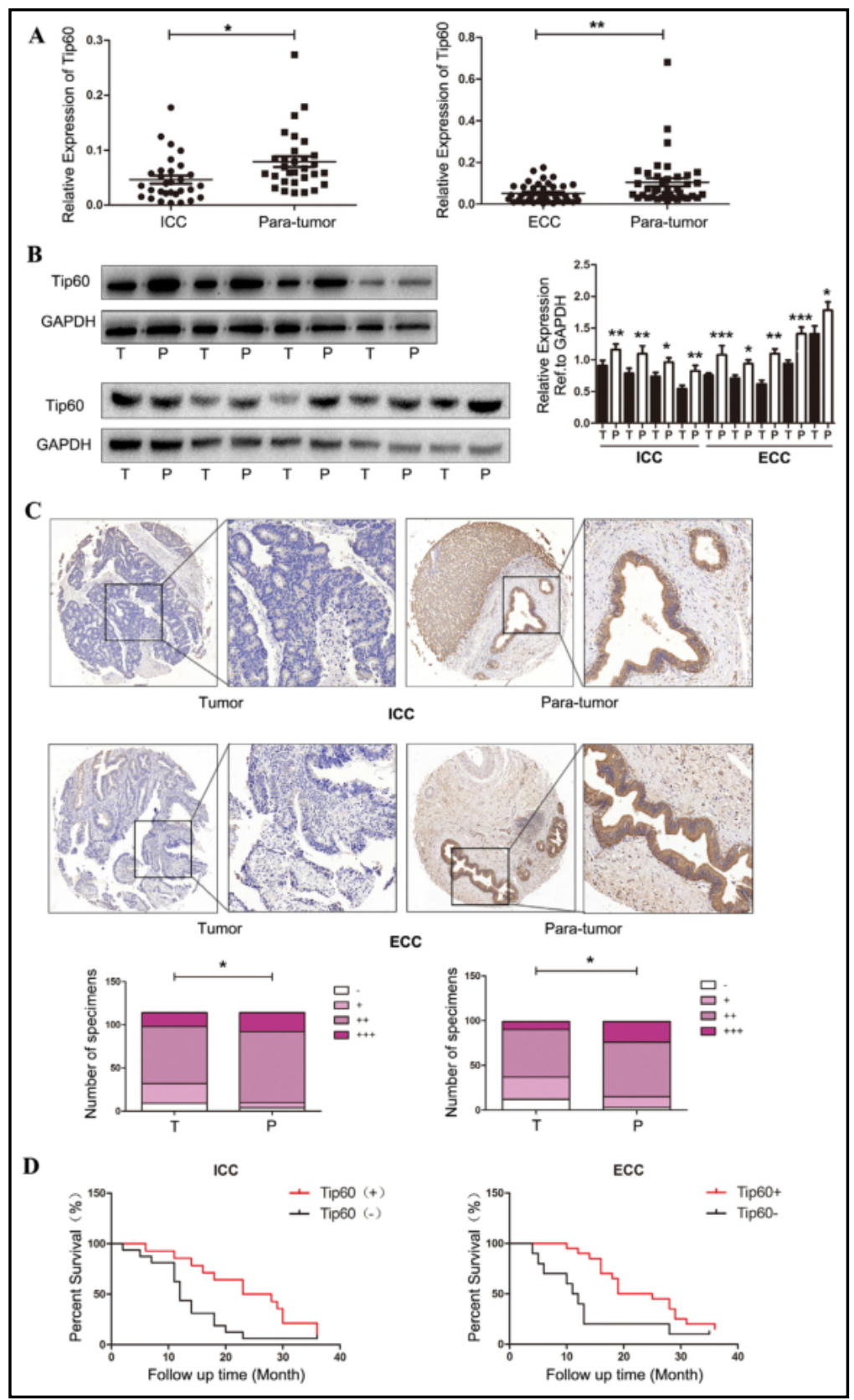

Fig. 1. Tip60 was down-regulated in CCA and served as a prognostic factor. (A)Tip60 expression in 30 ICC tumor tissues, 29 ECC tumor tissues, and the para-tumor tissues. (B) Protein expression of Tip60 was detected in both ICC and ECC tissues. (C) Representative immunohistochemistry stains of Tip60 in 114 ICC and 99 ECC samples. The percentage of tissue cores displaying no $(-)$, weak $(+)$, moderate $(++)$, or strong (+++) Tip60 staining in ICC, ECC, and the para-tumor tissues. (D) Kaplan-Meier survival curves of OS in 30 ICC and 29 ECC patients based on Tip60 mRNA expression. Data are presented as means \pm SEM and analyzed with Student's t test $\left({ }^{*} \mathrm{P}<0.05\right.$ $\left.{ }^{* *} \mathrm{P}<0.01,{ }^{* * *} \mathrm{P}<0.001\right) . \mathrm{T}=$ tumor, $\mathrm{P}=$ para-tumor. 


\section{Cellular Physiology Cell Physiol Biochem 2018;50:611-628 \begin{tabular}{ll|l} 
DOI: 10.1159/000494183 & $\begin{array}{l}\text { O } 2018 \text { The Author(s). Published by S. Karger AG, Basel } \\
\text { www.karger.com/cpb }\end{array}$
\end{tabular}

Correlation Between Tip60 and CCA Clinical Parameters

Based on the observed differences between ICC and ECC in pathology, we then analyzed the correlation between Tip60 expression and the clinicopathological factors of ICC and ECC. Subsequent analysis indicated that aberrant levels of Tip60 mRNA were correlated not only with tumor size but also with venous invasion in ICC (Table 2). The same results were found in ECC, although Tip60 expression was correlated with the higher tumor stage, indicating that Tip60 might play a role in CCA metastasis and proliferation (Table 3 ).

\section{Tip60 Suppressed the Proliferation of}

Cholangiocarcinoma Cells in vitro

To verify the function of Tip60 in vivo, western blot was used to detect the protein level of Tip60 (Fig. 2A) and qRT-PCR was conducted to detect the mRNA level of Tip60(Fig. 2B) in 4 CCA cells. According to the results, a significant decrease of Tip60 was found in in CCA cells. We constructed effective Tip60 knockdown cells (HUCCT1 and RBE) using small interference RNA (siRNA) target site (Si1, Si2) (Fig. 2C, D) and to further explore the role of Tip60 in tumor proliferation and metastasis, we next established Tip60 stably overexpressing cell lines (HCCC9810 and QBC939) (Fig. 2E, F).

As determined by the CCK-8 and colony formation assays, Tip60 depletion significantly enhanced CCA cell proliferation (Fig. 3A), while overexpression of Tip60 remarkably suppressed CCA cell proliferation (Fig. 3B). Similar results were observed in the EDU array (Fig. 3C). Cell cycle progression was determined following Tip60 up-regulation using flow cytometry. Tip60 up-regulation significantly reduced the proportion of cells in the G2 phase, and substantially increased the number of cells in the G1/S phase (Fig. 3D). We further detected low expression of cyclin D1, which is deemed as a key cell cycle protein, in the Tip60 up-regulated cells (Fig. 2E). Taken together, these data suggest that Tip60 is required for CCA proliferation.
Table 2. Clinicopathological relevance analysis of Tip60 expression in ICC patients

\begin{tabular}{|c|c|c|c|c|}
\hline \multirow{2}{*}{ Clinicopathologic Features } & \multicolumn{4}{|c|}{ Tip60 } \\
\hline & $\mathrm{n}$ & high & low & $\mathrm{P}$ \\
\hline \multicolumn{5}{|l|}{ Gender } \\
\hline Female & 11 & 6 & 5 & \multirow[b]{2}{*}{0.705} \\
\hline Male & 19 & 9 & 10 & \\
\hline \multicolumn{5}{|l|}{ Age } \\
\hline$<60$ & 11 & 7 & 4 & \multirow{2}{*}{0.256} \\
\hline$\geq 60$ & 19 & 8 & 11 & \\
\hline \multicolumn{5}{|l|}{ No. of tumor nodules } \\
\hline 1 & 18 & 10 & 8 & \multirow{2}{*}{0.456} \\
\hline$>1$ & 12 & 5 & 7 & \\
\hline \multicolumn{5}{|l|}{ Tumor size } \\
\hline$<5$ & 12 & 9 & 3 & \multirow{2}{*}{$0.025^{*}$} \\
\hline$\geq 5$ & 18 & 6 & 12 & \\
\hline \multicolumn{5}{|l|}{ Pathological stages } \\
\hline $\mathrm{I}+\mathrm{II}$ & 10 & 4 & 6 & \multirow{2}{*}{0.439} \\
\hline III + IV & 20 & 11 & 9 & \\
\hline \multicolumn{5}{|l|}{ Venous invasion } \\
\hline Absent & 17 & 11 & 5 & \multirow{2}{*}{$0.028^{*}$} \\
\hline Present & 13 & 4 & 10 & \\
\hline \multicolumn{5}{|l|}{ Tumor Stages } \\
\hline $\mathrm{I}+\mathrm{II}$ & 17 & 10 & 7 & \multirow{2}{*}{0.269} \\
\hline$\underline{\text { III + IV }}$ & 13 & 5 & 8 & \\
\hline
\end{tabular}

Table 3. Clinicopathological relevance analysis of Tip60 expression in ECC patients

\begin{tabular}{lcccc}
\hline Clinicopathologic Features & $\mathrm{n}$ & \multicolumn{4}{c}{ Tip60 } \\
& & high low & $\mathrm{P}$ \\
\hline Gender & & & & \\
Female & 11 & 7 & 4 & 0.316 \\
Male & 18 & 8 & 10 & \\
Age & & & & \\
$<60$ & 12 & 5 & 7 & 0.362 \\
$\geq 60$ & 17 & 10 & 7 & \\
No. of tumor nodules & & & & \\
1 & 23 & 13 & 10 & 0.311 \\
$>1$ & 6 & 2 & 4 & \\
Tumor size & & & & \\
$<3$ & 18 & 12 & 6 & $0.039^{*}$ \\
$\geq 3$ & 11 & 3 & 8 & \\
Pathological stages & & & & \\
I + II & 16 & 10 & 8 & 0.597 \\
III + IV & 13 & 5 & 6 & \\
Venous invasion & & & & \\
Absent & 12 & 9 & 3 & $0.035^{*}$ \\
Present & 17 & 6 & 11 & \\
Tumor Stages & & & & \\
I + II & 9 & 10 & 2 & $0.004^{*}$ \\
III + IV & 20 & 5 & 12 & \\
\hline & & & &
\end{tabular}


Fig. 2. (A) Protein expression of Tip60 was detected in 4 CCA cell lines and normal biliary epithelial cell line HIBEC. (B) The expression levels of Tip60 were determined by real-time PCR in 4 CCA cell lines as well as the normal biliary epithelial cell line HIBEC, with GAPDH as an internal control. (C) (D) Downregulation of Tip60 in RBE and HUCCT1 cells, detected by western blotting and QRT-PCR. (E)

(F) Overexpression of Tip60 in HCCC9810 and QBC939

detected

western blotting

assay and QRT-PCR. Data are shown as mean \pm SD. $\left({ }^{*} \mathrm{P}<0.05,{ }^{* *} \mathrm{P}<0.01,{ }^{* * *} \mathrm{P}<0.001\right)$. Si1= Small interference RNA site $1, \mathrm{Si} 2=$ Small interference RNA site $2, \mathrm{NC}=$ negative control, $\mathrm{Lv}=$ lentiviral vector overexpressing Tip60.

\section{Anti-invasion and Anti-migration Effects of Tip60 on Cholangiocarcinoma Cells in vitro}

To further confirm the role of Tip60 in CCA cell migration and invasion, the trans-well assay (Fig. 4A) revealed that cell invasion in CCA was significantly promoted by Tip60 downregulation. As expected, overexpression of Tip60 impeded cell migration and invasion in HCCC9810 and QBC939 cell lines. These results indicated that Tip60 can significantly inhibit CCA cell migration and invasion in vitro (Fig. 4B).

During the process of cell culture, we noticed that HCCC9810 cells with Tip60 overexpression became less spindle-like and fibroblastic, with a shorter pseudopodium compared to the negative controls. The inverse phenomenon was found in the RBE cells with Tip60 SiRNA, therefore, both HCCC9810 and RBE cells exhibited obvious morphological changes. In addition to the results of the migration and invasion results, these morphological changes led us to examine the expression of key epithelial-mesenchymal transition (EMT) markers. Western blotting analysis revealed that mesenchymal phenotype markers, including $\mathrm{N}$-cadherin and vimentin, were distinctly increased and E-cadherin was decreased in the Tip60 knockdown cells. The reverse results were found in the QBC939 and HCCC9810 cells which Tip60 was overexpressed (Fig. 4C). These results suggest that Tip60 suppresses the metastatic capacity of CCA cells.

\section{Evidence that Tip60 Might Inhibit the PI3K-AKT Pathway}

To address the mechanism by which Tip60 might suppress cell proliferation and invasion, we performed a phosphokinase array to identify possible Tip60 targets. This array contains 


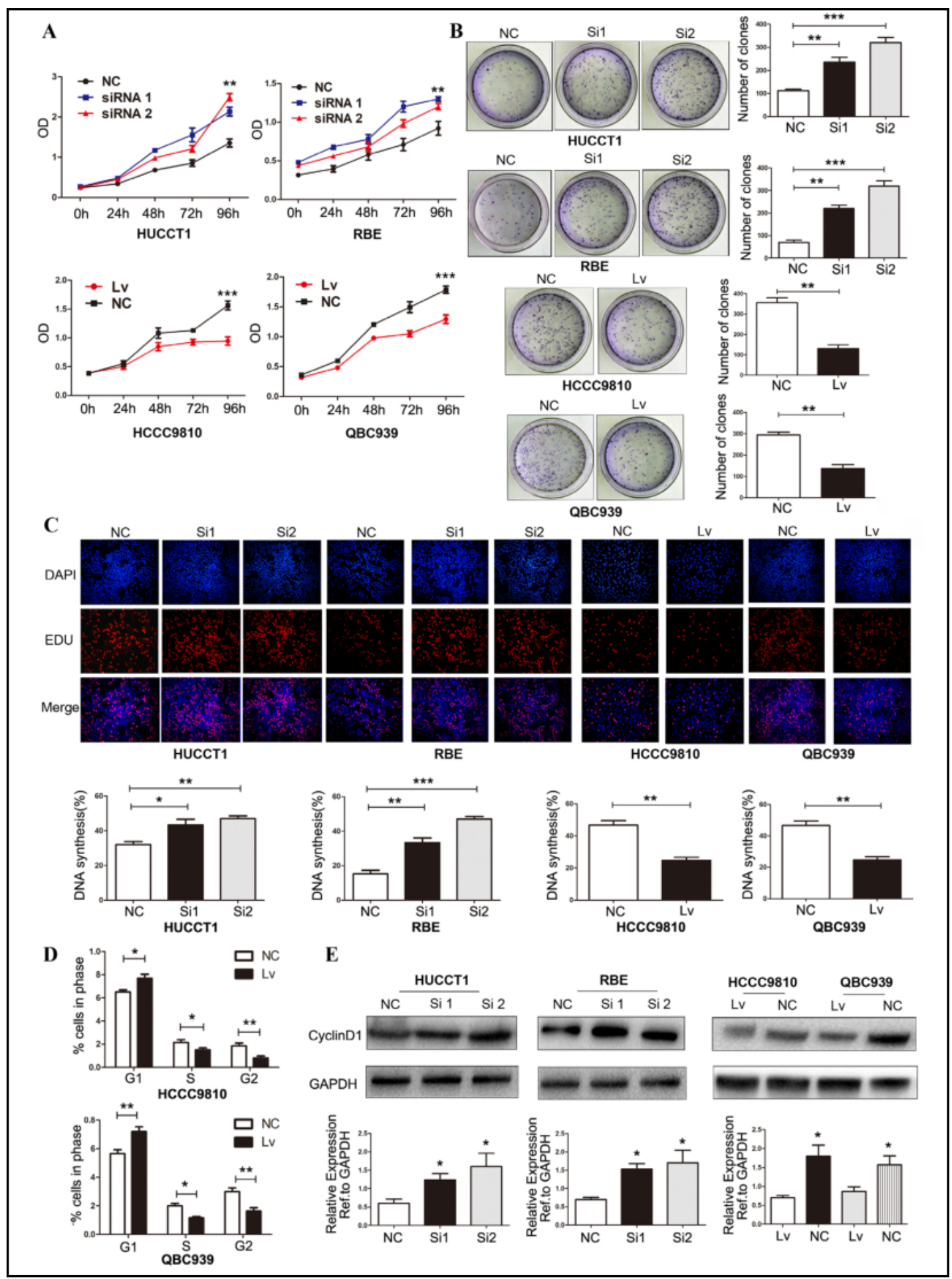

Fig. 3. Tip60 down-regulation promoted CCA cell proliferation and invasion in vitro. (A) CCK8 assays were employed to detect the proliferation of CCA cells. (B) Colony formation assay was employed to detect the proliferation of CCA cells. (C) EDU assay was applied to detect the proliferation of CCA cells. (D) FACS analysis of synchronized negative control and cells with Tip60 overexpression during cell cycle progression. (E) Western blotting of CyclinD1 protein levels in control and cells with Tip60 overexpression. Data are shown as mean $\pm \mathrm{SD}$ and were representative of three independent experiments. $\left({ }^{*} \mathrm{P}<0.05,{ }^{* *} \mathrm{P}<0.01,{ }^{* * *} \mathrm{P}<0.001\right)$. Si1= Small interference RNA site $1, \mathrm{Si} 2=$ Small interference RNA site 2, NC=Negative control, Lv= lentiviral vector overexpressing Tip60. 


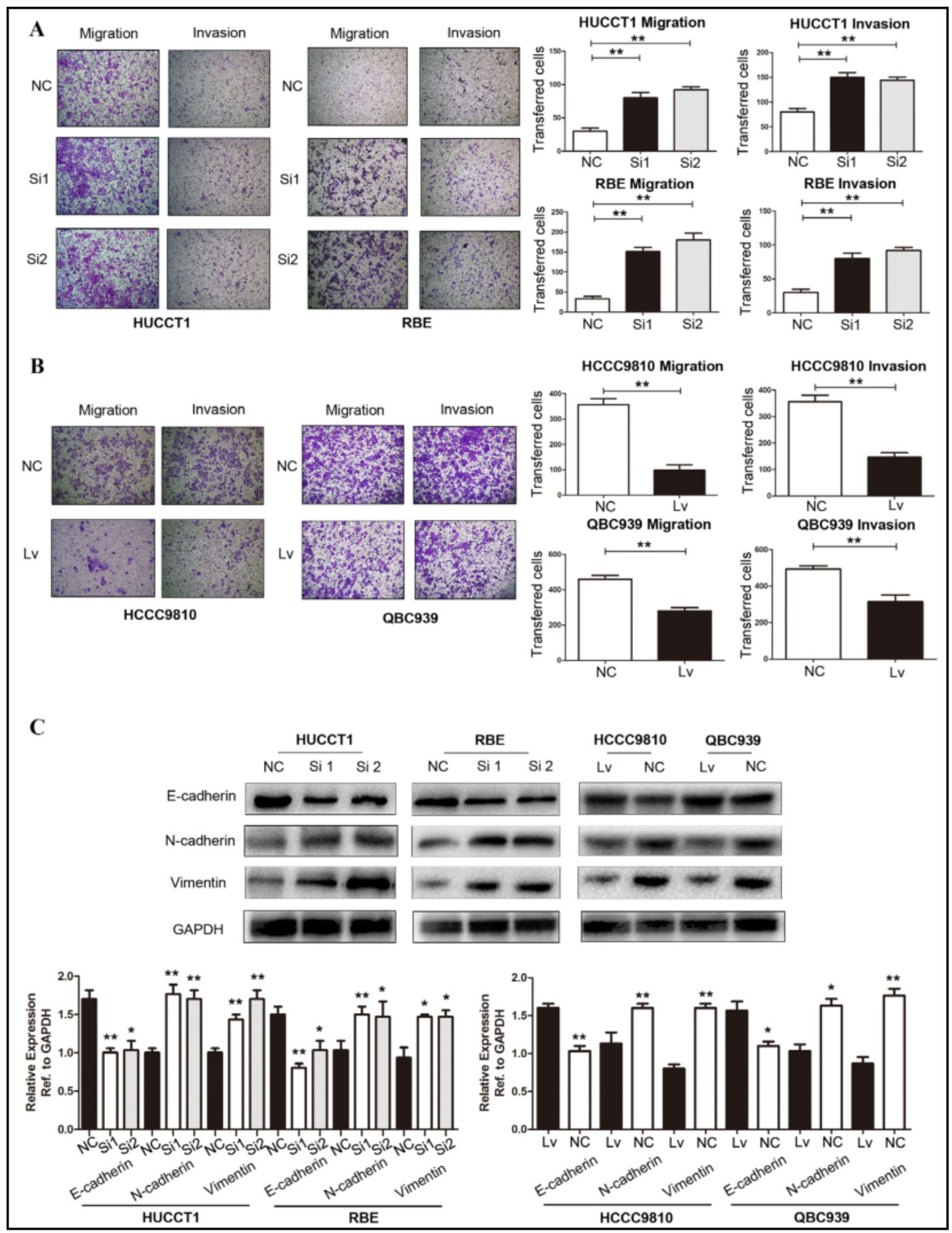

Fig. 4. Tip60 up-regulation promoted CCA cell migration and invasion in vitro. (A) Trans-well assay was conducted to assess the effect of Tip60 down-regulation on CCA cell migration and invasion. (B) Transwell assay was conducted to assess the effect of Tip60 up-regulation on CCA cell migration and invasion. (C) Western blotting was applied to identify the expression of E-cadherin, N-cadherin, and Vimentin. Data are shown as mean $\pm \mathrm{SD}$ and were representative of three independent experiments. $\left({ }^{*} \mathrm{P}<0.05,{ }^{* *} \mathrm{P}<0.01\right.$, $* * * \mathrm{P}<0.001) . \mathrm{Si} 1=$ Small interference RNA site $1, \mathrm{Si} 2=$ Small interference RNA site $2, \mathrm{NC}=$ negative control, $\mathrm{Lv}=$ lentiviral vector overexpressing Tip60. 


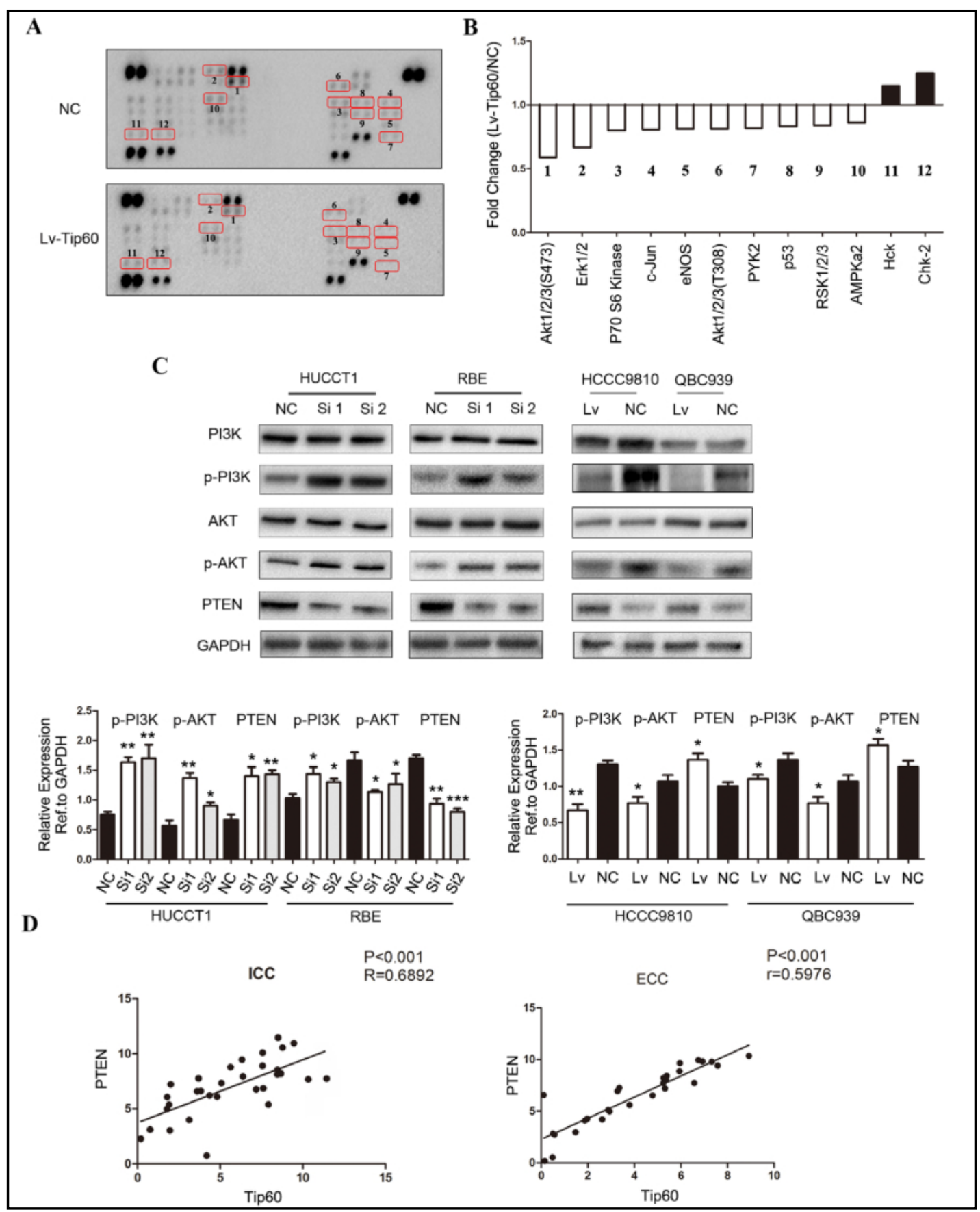

Fig. 5. Tip60 Inhibits the PI3K-AKT Pathway in CCA in vitro. (A) Phosphokinase signaling was screened in Tip60-upregulated vs. NC CCA cells using a phosphokinase array kit containing 46 phosphokinases. (B) The p-AKT (S473) is the dominant kinase, followed by Erk1/2. (C) PI3K, p-PI3K, AKT, p-AKT, and PTEN expression was examined by western blotting. Quantification of each protein was performed using GAPDH as an internal control. (D) Pearson correlation analysis was employed to calculate the correlation between the expression of Tip60 and PTEN in both ICC and ECC samples. Data are shown as mean \pm SD and were representative of three independent experiments. $\left({ }^{*} \mathrm{P}<0.05,{ }^{* *} \mathrm{P}<0.01,{ }^{* * *} \mathrm{P}<0.001\right)$. Si1= Small interference RNA site $1, \mathrm{Si} 2=$ Small interference RNA site $2, \mathrm{NC}=$ negative control, $\mathrm{Lv}=$ lentiviral vector overexpressing Tip60. 


\section{Cellular Physiology Cell Physiol Biochem 2018;50:611-628 \begin{tabular}{ll|l} 
DOI: 10.1159/000494183 & O 2018 The Author(s). Published by S. Karger AG, Basel \\
www.karger.com/cpb
\end{tabular} \\ Zhang et al.: Tip60 Suppresses Cholangiocarcinoma via Pt3K/Akt}

46 antibodies, each capable of binding cognate phosphorylated substrates in a cellular lysate, followed by chemiluminescent detection. To perform this assay, we used QBC939 CCA cells because these contain relatively low endogenous levels of Tip60 protein. The level of phosphorylated substrates, indicative of phosphokinase activation, in lysates from negative control (NC) cells was compared with lysates of cells wherein Tip60 was over-expressed with lentivirus (LV). Results, presented as the ratio of LV to NC cells, identified 14 phosphokinases that were inhibited $>1.2$-fold by Tip60. Among these, p-AKT (S473) was inactivated at the highest level, followed by Erk1/2 (Fig. 5A, B). This response of p-AKT, as well as that of its upstream activator p-PI3K, to up- and down-regulated Tip60 levels was corroborated by western blotting (Fig. 5C). Western blotting and qRT-PCR were also used to evaluate levels of PTEN (phosphatase tensin homologue), which regulates PI3K/AKT signaling, in response to Tip60 content; PTEN is a frequently mutated tumor suppressor (second only to p53) that regulates tumor proliferation, invasion, metastasis, and differentiation. As shown in Fig. 4C, PTEN was decreased during Tip60 knockdown and increased during Tip60 up-regulation, with Pearson analysis revealing that PTEN levels positively correlated with Tip60 levels in CCA tissues (Fig. 5D). These results suggest that Tip60 regulates PI3K-AKT signaling by modulating PTEN levels.

\section{Tip60 Regulated CCA Cell Proliferation and Metastasis via PI3K-AKT pathway}

Considering the above data, we speculated that Tip60 regulates CCA cell growth and metastasis though the PI3K-AKT pathway. To confirm our speculation, the well-known AKT activator, SC79, was used in QBC939 and HCCC9810 cells transfected with the Tip60 overexpressing lentivirus. The results showed that SC79 significantly promoted proliferation (Fig. 6A-C) and induced G1/S phase arrest of CCA cells overexpressing Tip60 (Fig. 6E). Moreover, activation (phosphorylation) of AKT with SC79 promoted the ability of CCA cells to metastasize (Fig. 6D). In addition, the expression of EMT and CyclinD1 was determined by western blotting, and the results showed that $\mathrm{N}$-cadherin, vimentin, and cyclinD1 were increased and E-cadherin was decreased when the HCCC9810 and QBC939 cells were treated with sc79(Fig. 6F). We next investigated whether E-cadherin was correlated with the Tip60 level in ICC and ECC tissues. Pearson analysis was applied to reveal a positive correlation between E-cadherin and Tip60 (Fig. 5G).

Tip60 Attenuated the Proliferation and Metastasis of CCA Cells in a Nude Mouse Xenograft Model

To further explore the effects of Tip60 in vivo, we established a xenograft nude mouse model using QBC939 cells overexpressing Tip60 (Fig. 7A). Compared with the control group, tumor weight and volume in Tip60 overexpressing mice were significantly reduced (Fig. 7B, C). Western blotting analysis also revealed that Tip60 expression was significantly higher than in the control group (Fig. 7D). To verify the role of Tip60 in tumor metastasis, Tip60 overexpressing QBC939 cells were injected via the tail vein. The results showed an observable decrease in the number of mice with lung metastasis and fewer metastatic nodules in the pulmonary tissues of each mouse (Fig. 7E) compared with the control group. We further investigated metastasis by immunohistochemistry; the results are presented in Fig. 7F. These observations suggested that Tip60 is a potent inhibitor of CCA metastasis. Taken together, these findings further indicated the tumor suppressive effect of Tip60 on CCA both in vitro and in vivo. 


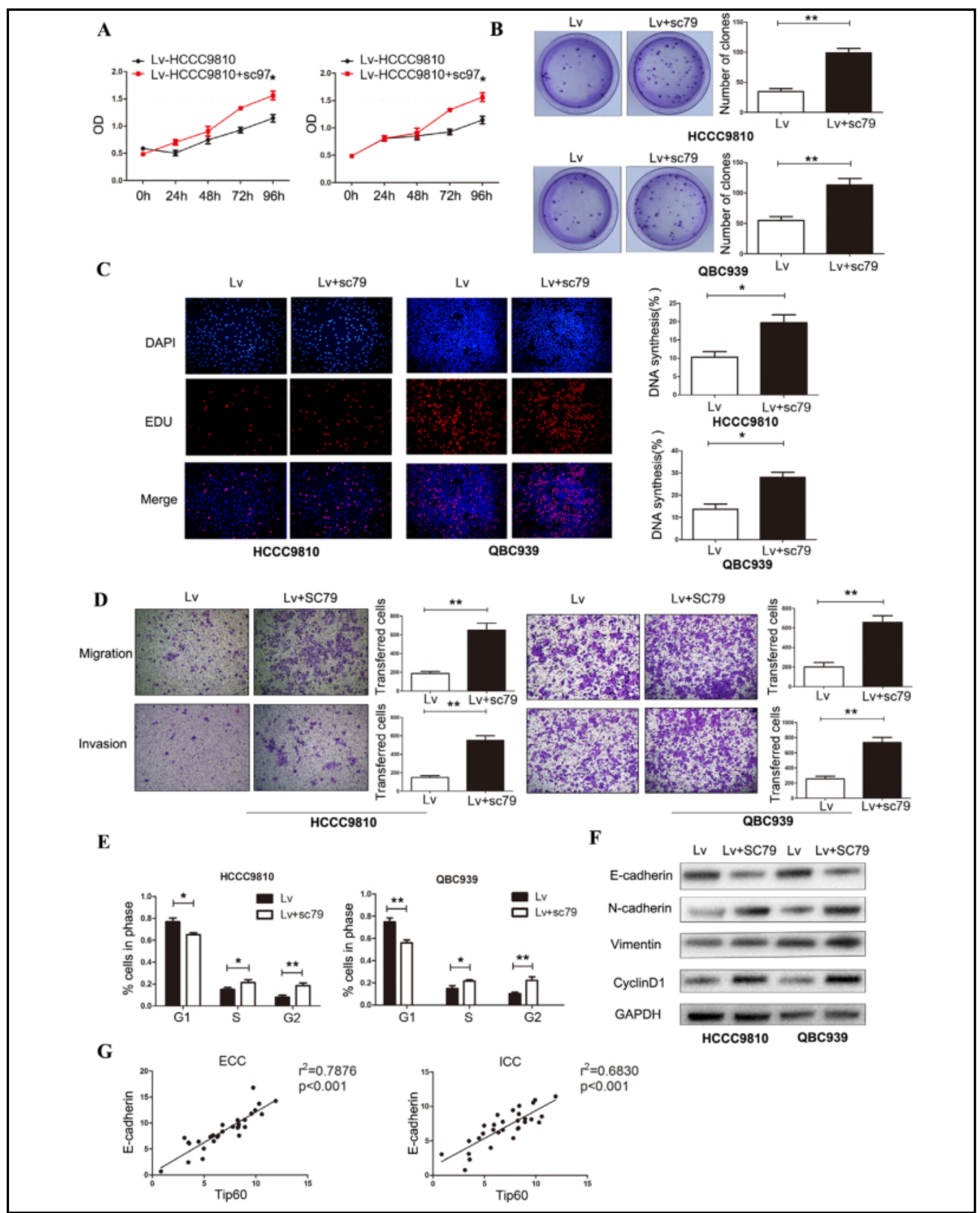

Fig. 6. Tip60 regulates CCA cell proliferation and invasion in a PI3K-AKT-dependent manner. (A) CCK8 assay was employed to detect the proliferation of CCA cells. (B) Colony formation assay was employed to detect the proliferation of CCA cells. (C) EDU assay was applied to detect the proliferation of CCA cells. (D) Trans-well assay was conducted to assess the effect of Tip60 down-regulation on CCA cell migration and invasion. (E) FACS analysis of synchronized negative control and cells with Tip60 overexpression during cell cycle progression. (F) E-cadherin, N-cadherin, vimentin, and cyclinD1 expression were examined by western blotting. Quantification of each protein was performed using GAPDH as an internal control. (G) Pearson correlation analysis was employed to calculate the correlation between the expression of Tip60 and E-cadherin in both ICC and ECC samples. Data are shown as mean \pm SD and were representative of three independent experiments. $\left({ }^{*} \mathrm{P}<0.05,{ }^{* *} \mathrm{P}<0.01,{ }^{* * *} \mathrm{P}<0.001\right)$. Si1 $=$ Small interference RNA site $1, \mathrm{Si} 2=$ Small interference RNA site $2, \mathrm{NC}=$ negative control, $\mathrm{Lv}=$ lentiviral vector overexpressing Tip60.

\section{KARGER}




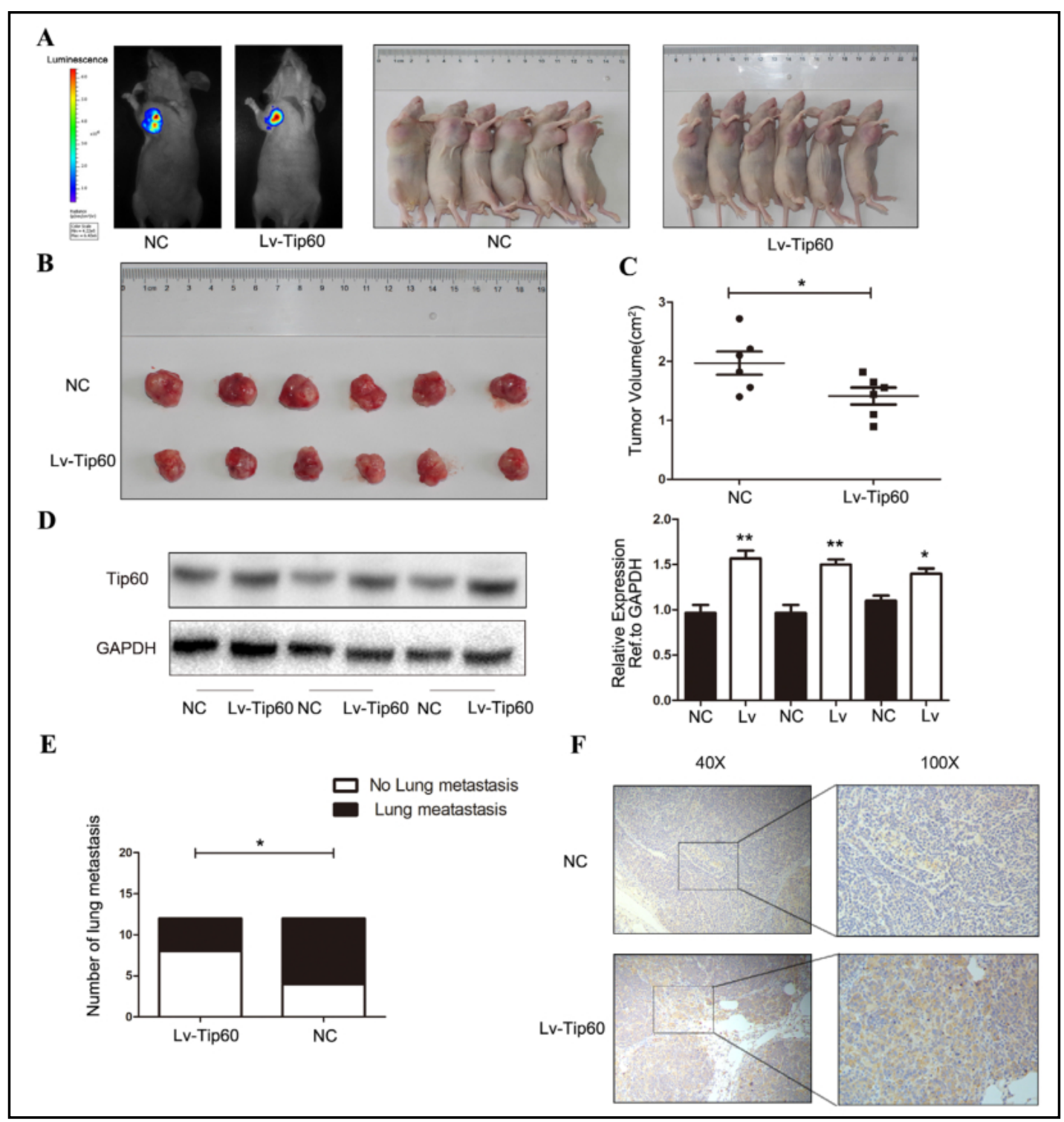

Fig. 7. Tip60 attenuated the growth and metastasis of CCA cells in a nude mouse xenograft model. (A) Nude mice were subcutaneously transplanted with cells stably overexpressing Tip60. (B) A representative tumor from each group. (C) The weight and volume of each tumor was calculated. (D) Tip60 was examined by western blotting to determine protein expression. Quantification of each protein was performed using GAPDH as an internal control. (E) Lung metastasis was recorded and analyzed in each group. (F) A representative immunohistochemistry stain of lung tissues with or without metastasis. Data are shown as mean $\pm \mathrm{SD} .\left({ }^{*} \mathrm{P}<0.05,{ }^{* *} \mathrm{P}<0.01,{ }^{* * *} \mathrm{P}<0.001\right)$. $\mathrm{NC}=$ Negative control, $\mathrm{Lv}=$ lentiviral vector overexpressing Tip60.

\section{Discussion}

Cholangiocarcinoma is the second most common primary hepatic tumor, and accounts for nearly $3 \%$ of all gastrointestinal cancers diagnosed worldwide [22, 23]. Although incidence rates for ICC vary widely, the highest rates have been reported in Thailand, China, and other parts of Asia [24]. At present, surgical resection with adjuvant chemotherapy results in a better outcome in patients with CCA, however, overall survival time is still disappointing. Worldwide, CCA remains the highest ranked in terms of increased mortality for the period 
between 1990 and 2009 [25]. The classifications distinguish intra- (ICC) or extra-hepatic CCA (ECC), and ECC is further divided into hilar CCA located at the liver hilum, or distal CCA located near the pancreas. Current studies have investigated the molecular markers in CCA regardless of location [26]. It is difficult to ignore the differences between ICC and ECC regarding risk factors, epidemiology, growth patterns, symptoms, incidence of metastases, staging, treatment, and survival. This study is the first to determine Tip60 expression in both ICC and ECC, and to analyze the correlation between Tip60 expression level and clinical parameters, including prognosis.

It is well known that acetylation is a major modification involved in gene regulation, genome maintenance, and metabolism. MYST family members have a significant effect on chromatin structure in the eukaryotic nucleus by playing a key role in the posttranslational modification of histones [27]. Tip60, a member of the MYST family, is the acetyltransferase catalytic subunit of the Human NuA4 complex. Tip60 has been shown to remodel chromatin in several diseases, including several cancers such as lymphoma, melanoma, breast, colon, and lung cancer [28]. Many studies have shown that Tip60 may function as a tumor suppressor $[29,30]$. Hu et al. reported that during the blastocyst stage of development, lack of Tip60 promoted embryo lethality, showing that Tip60 is an essential gene [31]. Tip60 is a vital protein and its function cannot be compensated for by other members of the MYST family.

In the present study, we revealed that Tip60 expression was significantly down-regulated in both ICC and ECC tissues. Further, we found that down-regulation of Tip60 expression in ICC resulted in larger tumor size and venous invasion. In ECC, large tumor size, venous invasion, and advanced TNM stage was correlated with the down-regulation of Tip60. It is worth noting that the choice of a 5-cm cutoff in ECC and a 3-cm cutoff in ICC was based on accumulating data indicating better prognosis for smaller tumors. In the prognosis analysis, down-regulation of Tip60 expression correlated with worse overall survival (OS) time in both ICC and ECC. These results revealed that Tip60 might exhibit anti-oncogenic functions in ICC and ECC. Further, in vitro and in vivo experiments demonstrated that Tip60 inhibited CCA cell proliferation and metastasis.

Phosphokinase array indicated that PI3K/AKT activation was negative correlated with the Tip60 expression. Therefore, we speculated that Tip60 was capable of suppressing CCA proliferation and metastasis by decreasing PI3K/AKT phosphorylation. As previous studies showed that the activity of the AKT signaling pathway increased along with the under-expression of TIP60[32], and histone levels may inhibit tumorigenesis through deactivation of the AKT cascade [33]. Our results suggested that the marker of AKT activation, phosphorylation at Ser473, was inhibited when TIP60 was overexpressed. As expected, the inhibitory effect of Tip60 up-regulation on CCA cell growth and invasion was significantly rescued by PI3K/AKT activation. AKT is activated in many human cancers, endowing tumor cells with motile and invasive properties [34]. The PI3K/AKT signaling pathway is also an important intracellular signal transduction pathway, participating in regulation of cell apoptosis and proliferation $[35,36]$. To clarify whether the downstream target of Tip60 suppressed CCA proliferation and metastasis, we demonstrated that Tip60 inhibited EMT and CyclinD1 expression though the PI3K/AKT pathway in vitro.

AKT, a promoter of the PI3K/AKT pathway is negatively regulated by a group of lipid phosphatases, of which PTEN is the main representative. The importance of PTEN in cellular function is underscored by the frequency of its deregulation in cancer [37, 38]. PTEN tumorsuppressor activity depends largely on its lipid phosphatase activity, which opposes PI3K/ AKT activation. As such, PTEN regulates many cellular processes, including proliferation, survival, energy metabolism, cellular architecture, and motility [39, 40]. More than a decade of research has expanded our knowledge regarding how PTEN is controlled at the transcriptional level, as well as by numerous posttranscriptional modifications that regulate its enzymatic activity, protein stability, and cellular location [41]. Although the role of PTEN in cancer has long been appreciated, it is also emerging as an important factor in other diseases such as diabetes and autism spectrum disorders. In the current study, we demonstrated that the expression level of PTEN was correlated with Tip60 expression in clinical CCA samples. 


\section{Cellular Physiology Cell Physiol Biochem 2018;50:611-628

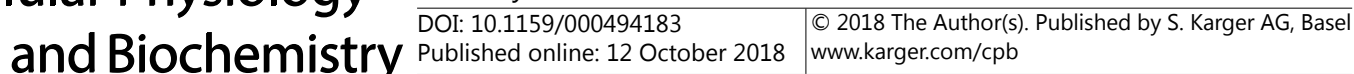 \\ Zhang et al.: Tip60 Suppresses Cholangiocarcinoma via Pt3K/Akt}

In addition, the western blotting and IHC results showed that there is a positive correlation between Tip60 and PTEN. These results suggested that PTEN may play an important role in Tip60 regulation of the PI3K/AKT pathway.

\section{Conclusion}

In conclusion, we determined that Tip60 is significantly down-regulated in CCA tissues and cells, and acts as a tumor suppressor in CCA progression. In addition, our study suggested a role for Tip60 in regulation of the PI3K-Akt pathway and was a positive correlation between Tip60 and PTEN. Tip60 may serve as a promising therapeutic target or prognostic biomarker for CCA.

\section{Acknowledgements}

We thank all authors included in this research. We also thank the National Science Foundation of China (NSFC) (81670570), and key research and development program of Jiangsu Province (BE2016789).

\section{Disclosure Statement}

The authors declare no conflict of interests.

\section{References}

1 Shin HR, Oh JK, Masuyer E, Curado MP, Bouvard V, Fang YY, Wiangnon S, Sripa B, Hong ST: Epidemiology of cholangiocarcinoma: an update focusing on risk factors. Cancer Sci 2010;101:579-585.

$>2$ Tyson GL, El-Serag HB: Risk factors for cholangiocarcinoma. Hepatology 2011;54:173-184.

3 Bismuth H, Nakache R, Diamond T: Management strategies in resection for hilar cholangiocarcinoma. Ann Surg 1992;215:31-38

4 Olnes MJ, Erlich R: A review and update on cholangiocarcinoma. Oncology 2004;66:167-179.

$>5$ Razumilava N, Gores GJ: Cholangiocarcinoma. Lancet 2014;383:2168-2179.

6 Allard S, Utley RT, Savard J, Clarke A, Grant P, Brandl CJ, Pillus L, Workman JL, Cote J: NuA4, an essential transcription adaptor/histone $\mathrm{H} 4$ acetyltransferase complex containing Esa1p and the ATM-related cofactor Tra1p. EMBO J 1999;18:5108-5119.

7 Bassi C, Li YT, Khu K, Mateo F, Baniasadi PS, Elia A, Mason J, Stambolic V, Pujana MA, Mak TW, Gorrini C: The acetyltransferase Tip60 contributes to mammary tumorigenesis by modulating DNA repair. Cell Death Differ 2016;23:1198-1208.

-8 Jacquet K, Fradet-Turcotte A, Avvakumov N, Lambert JP, Roques C, Pandita RK, Paquet E, Herst P, Gingras AC, Pandita TK, Legube G, Doyon Y, Durocher D, Cote J: The TIP60 Complex Regulates Bivalent Chromatin Recognition by 53BP1 through Direct H4K20me Binding and H2AK15 Acetylation. Mol Cell 2016;62:409421.

-9 Lin SY, Li TY, Liu Q, Zhang C, Li X, Chen Y, Zhang SM, Lian G, Liu Q, Ruan K, Wang Z, Zhang CS, Chien KY, Wu J, Li Q, Han J, Lin SC: GSK3-TIP60-ULK1 signaling pathway links growth factor deprivation to autophagy. Science 2012;336:477-481.

10 Zhao H, Jin S, Gewirtz AM: The histone acetyltransferase TIP60 interacts with c-Myb and inactivates its transcriptional activity in human leukemia. J Biol Chem 2012;287:925-934.

11 ME LL, Vidal F, Gallardo D, Diaz-Fuertes M, Rojo F, Cuatrecasas M, Lopez-Vicente L, Kondoh H, Blanco C, Carnero A, Ramon y Cajal S: New p53 related genes in human tumors: significant downregulation in colon and lung carcinomas. Oncol Rep 2006;16:603-608. 


\section{Cellular Physiology Cell Physiol Biochem 2018;50:611-628 \begin{tabular}{ll|l} 
DOI: 10.1159/000494183 & $\begin{array}{l}\text { O } 2018 \text { The Author(s). Published by S. Karger AG, Basel } \\
\text { www.karger.com/cpb }\end{array}$ \\
\hline and Biochemistry
\end{tabular}

12 Gorrini C, Squatrito M, Luise C, Syed N, Perna D, Wark L, Martinato F, Sardella D, Verrecchia A, Bennett S, Confalonieri S, Cesaroni M, Marchesi F, Gasco M, Scanziani E, Capra M, Mai S, Nuciforo P, Crook T, Lough J, Amati B: Tip60 is a haplo-insufficient tumour suppressor required for an oncogene-induced DNA damage response. Nature 2007;448:1063-1067.

13 Chan HM, Narita M, Lowe SW, Livingston DM: The p400 E1A-associated protein is a novel component of the p53 --> p21 senescence pathway. Genes Dev 2005;19:196-201.

14 Monden T, Wondisford FE, Hollenberg AN: Isolation and characterization of a novel ligand-dependent thyroid hormone receptor-coactivating protein. J Biol Chem 1997;272:29834-29841.

15 Chen FE, Ghosh G: Regulation of DNA binding by Rel/NF-kappaB transcription factors: structural views. Oncogene 1999;18:6845-6852.

-16 Frank SR, Parisi T, Taubert S, Fernandez P, Fuchs M, Chan HM, Livingston DM, Amati B: MYC recruits the TIP60 histone acetyltransferase complex to chromatin. EMBO Rep 2003;4:575-580.

17 Liu N, Wang J, Wang J, Wang R, Liu Z, Yu Y, Lu H: ING5 is a Tip60 cofactor that acetylates p53 in response to DNA damage. Cancer Res 2013;73:3749-3760.

18 Charvet C, Wissler M, Brauns-Schubert P, Wang SJ, Tang Y, Sigloch FC, Mellert H, Brandenburg M, Lindner SE, Breit B, Green DR, McMahon SB, Borner C, Gu W, Maurer U: Phosphorylation of Tip60 by GSK-3 determines the induction of PUMA and apoptosis by p53. Mol Cell 2011;42:584-596.

19 Miyamoto N, Izumi H, Noguchi T, Nakajima Y, Ohmiya Y, Shiota M, Kidani A, Tawara A, Kohno K: Tip60 is regulated by circadian transcription factor clock and is involved in cisplatin resistance. J Biol Chem 2008;283:18218-18226.

20 Bohanes P, Labonte MJ, Lenz HJ: A review of excision repair cross-complementation group 1 in colorectal cancer. Clin Colorectal Cancer 2011;10:157-164.

-21 Takino T, Saeki H, Miyamori H, Kudo T, Sato H: Inhibition of membrane-type 1 matrix metalloproteinase at cell-matrix adhesions. Cancer Res 2007;67:11621-11629.

-22 Khan SA, Taylor-Robinson SD, Toledano MB, Beck A, Elliott P, Thomas HC: Changing international trends in mortality rates for liver, biliary and pancreatic tumours. J Hepatol 2002;37:806-813.

23 Vauthey JN, Blumgart LH: Recent advances in the management of cholangiocarcinomas. Semin Liver Dis 1994;14:109-114.

24 Lim JH, Park CK: Pathology of cholangiocarcinoma. Abdom Imaging 2004;29:540-547.

-25 Committee ACPRW, Sawyers CL, Abate-Shen C, Anderson KC, Barker A, Baselga J, Berger NA, Foti M, Jemal A, Lawrence TS, Li CI, Mardis ER, Neumann PJ, Pardoll DM, Prendergast GC, Reed JC, Weiner GJ: AACR Cancer Progress Report 2013. Clin Cancer Res 2013;19:S4-98.

-26 Ruys AT, Groot Koerkamp B, Wiggers JK, Klumpen HJ, ten Kate FJ, van Gulik TM: Prognostic biomarkers in patients with resected cholangiocarcinoma: a systematic review and meta-analysis. Ann Surg Oncol 2014;21:487-500.

27 Avvakumov N, Cote J: The MYST family of histone acetyltransferases and their intimate links to cancer. Oncogene 2007;26:5395-5407.

-28 Utley RT, Cote J: The MYST family of histone acetyltransferases. Curr Top Microbiol Immunol 2003;274:203-236.

-29 Judes G, Rifai K, Ngollo M, Daures M, Bignon YJ, Penault-Llorca F, Bernard-Gallon D: A bivalent role of TIP60 histone acetyl transferase in human cancer. Epigenomics 2015;7:1351-1363.

30 Takino T, Nakada M, Li Z, Yoshimoto T, Domoto T, Sato H: Tip60 regulates MT1-MMP transcription and invasion of glioblastoma cells through NF-kappaB pathway. Clin Exp Metastasis 2016;33:45-52.

31 Hu Y, Fisher JB, Koprowski S, McAllister D, Kim MS, Lough J: Homozygous disruption of the Tip60 gene causes early embryonic lethality. Dev Dyn 2009;238:2912-2921.

-32 Yang Y, Sun J, Chen T, Tao Z, Zhang X, Tian F, Zhou X, Lu D: Tat-interactive Protein-60KDA (TIP60) Regulates the Tumorigenesis of Lung Cancer In vitro. J Cancer 2017;8:2277-2281.

33 Makarevic J, Tawanaie N, Juengel E, Reiter M, Mani J, Tsaur I, Bartsch G, Haferkamp A, Blaheta RA: Crosscommunication between histone $\mathrm{H} 3$ and $\mathrm{H} 4$ acetylation and Akt-mTOR signalling in prostate cancer cells. J Cell Mol Med 2014;18:1460-1466.

-34 Zhang Y, Subbaiah VK, Rajagopalan D, Tham CY, Abdullah LN, Toh TB, Gong M, Tan TZ, Jadhav SP, Pandey AK, Karnani N, Chow EK, Thiery JP, Jha S: TIP60 inhibits metastasis by ablating DNMT1-SNAIL2-driven epithelial-mesenchymal transition program. J Mol Cell Biol 2016; DOI:10.1093/jmcb/mjw038. 


\section{Cellular Physiology Cell Physiol Biochem 2018;50:611-628

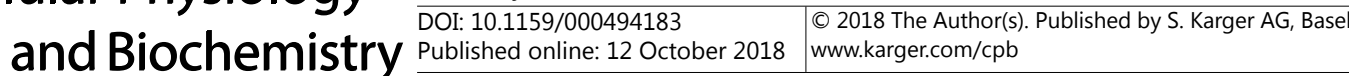

-35 Li T, Zhao X, Mo Z, Huang W, Yan H, Ling Z, Ye Y: Formononetin promotes cell cycle arrest via downregulation of Akt/Cyclin D1/CDK4 in human prostate cancer cells. Cell Physiol Biochem 2014;34:1351-1358.

-36 Serrano ML, Sanchez-Gomez M, Bravo MM, Yakar S, LeRoith D: Differential expression of IGF-I and insulin receptor isoforms in HPV positive and negative human cervical cancer cell lines. Horm Metab Res 2008;40:661-667.

-37 Yoshimi A, Goyama S, Watanabe-Okochi N, Yoshiki Y, Nannya Y, Nitta E, Arai S, Sato T, Shimabe M, Nakagawa M, Imai Y, Kitamura T, Kurokawa M: Evi1 represses PTEN expression and activates PI3K/AKT/mTOR via interactions with polycomb proteins. Blood 2011;117:3617-3628.

38 Li J, Yen C, Liaw D, Podsypanina K, Bose S, Wang SI, Puc J, Miliaresis C, Rodgers L, McCombie R, Bigner SH, Giovanella BC, Ittmann M, Tycko B, Hibshoosh H, Wigler MH, Parsons R: PTEN, a putative protein tyrosine phosphatase gene mutated in human brain, breast, and prostate cancer. Science 1997;275:1943-1947.

39 Bassi C, Ho J, Srikumar T, Dowling RJ, Gorrini C, Miller SJ, Mak TW, Neel BG, Raught B, Stambolic V: Nuclear PTEN controls DNA repair and sensitivity to genotoxic stress. Science 2013;341:395-399.

-40 Chagpar RB, Links PH, Pastor MC, Furber LA, Hawrysh AD, Chamberlain MD, Anderson DH: Direct positive regulation of PTEN by the p85 subunit of phosphatidylinositol 3-kinase. Proc Natl Acad Sci U S A 2010;107:5471-5476.

41 Wang L, Wang WL, Zhang Y, Guo SP, Zhang J, Li QL: Epigenetic and genetic alterations of PTEN in hepatocellular carcinoma. Hepatol Res 2007;37:389-396. 